\title{
RECONHECIMENTO DE COMPETÊNCIAS PRÉVIAS DE ALUNOS DE CURSOS TÉCNICOS A DISTÂNCIA PARA PROPICIAR UMA APRENDIZAGEM SIGNIFICATIVA
}

\author{
GOIÂNIA/GO MAIO/2018
PAULO DE SÁ FILHO - IfGoiano - prof.paulo@hotmail.com.br
Marco Antônio de Carvalho - IfGoiano - marco.carvalho@ifgoiano.edu.br
Gessyca Pereira da Silva - SENAI - gessyca.hby@gmail.com \\ Tipo: Relato de Experiência Inovadora (EI) \\ Categoria: Pesquisa e Avaliação \\ Setor Educacional: EDUCAÇÃO MÉDIA E TECNOLÓGICA, EDUCAÇÃO CORPORATIVA, \\ EDUCAÇÃO CONTINUADA EM GERAL

\begin{abstract}
RESUMO
Este artigo tem como objetivo apresentar um questionário desenvolvido como instrumento para identificar o perfil de alunos, bem com suas competências previas, que estão relacionadas aos cursos técnicos a distância que eles vão realizar. Assim, visando contribuir com os docentes na formulação de situações de aprendizagem que levem em consideração os saberes prévios dos alunos, desaguando dessa maneira em processo de ensino-aprendizagem eficiente e que contribua especialmente na construção de competências, propiciando uma aprendizagem significativa aos educandos.
\end{abstract}

Palavras-chave: Aprendizagem Significativa; Competência; Técnicos a Distância

\section{AGRADECIMENTOS}

AGRADECEMOS A DEUS O NOSSO AUTOR DA VIDA E NOSSA FAMÍLIA. 


\section{Aprendizagem Significativa e Ensino por Competências}

A aprendizagem significativa não é o tipo de aprendizagem que se reduz em apenas apresentações de conteúdos descontextualizados. Ela é muito importante em todas as modalidades de ensino, pois, nesse caso, os professores fazem com que os alunos se apropriem dos conhecimentos para compreender as situações enfrentadas no seu cotidiano, sendo capazes, dessa maneira, de pensar alternativas de atuação.

Uma das maneiras de colocar em prática a Aprendizagem Significativa, é o ensino por competências. De acordo com Bronckart e Dolz (2004), a ideia de competência é muito utilizada na formação profissional, já que considera-se melhores maneiras de qualificar esse indivíduo para enfrentar as situações variáveis de trabalho. Entretanto, existem diversas formas de compreender essa concepção de ensino. Um dos principais autores que estudam o ensino por competência é o sociólogo suíço Philippe Perrenoud.

Em uma entrevista no programa Roda Viva, em que o conteúdo foi transcrito e está no site da FAPESP (Fundação de Amparo à Pesquisa do Estado de São Paulo), Perrenoud (2001), ao se referir às competências, diz que

É importante marcar a diferença entre o conceito de competência que a escola quer desenvolver e o uso desse conceito pelas empresas atualmente. É preciso diferenciar. Há um lado negativo da evolução do mercado de trabalho, do mundo econômico em que a noção de "competência" tomou o lugar da noção da "qualificação", individualizou o tratamento das pessoas, criou desigualdades, criou a precariedade, criou flexibilidade em prejuízo do trabalhador. É a realidade. Pode-se, então, usar o conceito de competência, de gestão de recursos humanos contra as pessoas. Ao mesmo tempo, até no mundo da empresa, o reconhecimento do conceito de competência é o reconhecimento da complexidade do trabalho até nos trabalhos menos qualificados, da inteligência no trabalho de todos os trabalhadores, mesmo dos que controlam portões e estacionamentos, dos que servem na lanchonete. Todos fazem escolhas, todos devem fazer julgamentos, todos constroem algo, todos avaliam situações que não estão nos manuais, não-padronizadas, todos se arriscam a pensar mesmo em algo simples, ao contrário do que se pensa. Portanto devemos reconhecer que a competência no trabalho é uma forma de valorização do sujeito que pensa. Primeiro, não é um savoirfaire (saber-fazer) de baixo nível. A inteligência humana está presente nas competências e a escola segue o mesmo objetivo nisso.

Nesse trecho, o autor refere-se aos trabalhadores que, em seu cotidiano de trabalho, devem observar e analisar as mais diversas situações, identificar problemas, buscar soluções, fazer escolhas, avaliar os recursos que ele se dispõe e os resultados de suas 
ações, levando em conta os riscos que irá correr e as vantagens que terá, conforme a sua decisão. Fazendo isso, a complexidade do trabalho é considerada, como também a inteligência para desenvolvê-lo com qualidade. Pode-se dizer, então, que, dessa maneira, considerar a competência do sujeito no trabalho é também considerar e valorizar o sujeito que pensa. De acordo com Perrenoud,

A inteligência humana está presente nas competências e a escola segue o mesmo objetivo nisso. Ela não é responsável pelas relações de força que se travam no mundo. A escola não pode mudar o capitalismo e a sociedade. Ela faz parte da sociedade. Não se deve responsabilizá-la, mas não se pode pedir que ela aumente o problema. Daí, é crucial que competências desenvolvidas na escola não sejam habilidades para funções de trabalho ou locais particulares, mas que sejam competências de alto nível. Não concebo competência como uma habilidade específica, mas como a capacidade de analisar uma situação, de compreender de onde vem essa situação, qual é o problema, quais são as soluções, que estratégia adotar, onde há recursos, com quem contar, quais são os riscos, quais são as vantagens. Competência é, portanto, pensar em situações complexas (Idem. Ibidem).

Pensar em situações complexas significa usar o "saber", o conhecimento, para tomar decisões. Dessa forma, o conceito de competência adquire um nível de complexidade e, segundo o autor, a sua definição depende dos graus de complexidade e de situações a enfrentar. Portanto,

Todo o sistema educativo, em toda parte, é uma imensa propedêutica de preparação aos estudos longos. Ainda não saímos dessa lógica. As universidades dizem: "Queremos alunos com isso em lingüística, matemática etc. Do contrário, não conseguimos elaborar um programa de primeiro e segundo ciclos universitários." As escolas de segundo grau dizem para a escola média: "Queremos quem estudou álgebra, história e gramática." E a escola média diz para a escola primária: "Queremos alunos que, aos doze anos, saibam..." Essa lógica vem de cima. E esse "de cima" não é a vida, são os estudos superiores. (...) O ensino universitário é uma importante alavanca social, que considera mais importante alunos preparados para estudar que preparados para a vida. É preciso equilibrar essas forças centradas em saberes abstratos, em preparo para estudos longos, com outras considerações, outros argumentos (Idem. Ibidem).

Analisando dessa forma, percebe-se que possuir uma elite minoritária na sociedade não é a forma mais inteligente de lidar com a nossa realidade, já que hoje precisamos de muitas pessoas qualificadas em todas as profissões e campos sociais. Nos deparar com 
uma minoria que obteve condições de se manter em uma longa preparação com estudos e em uma grande maioria que obteve uma educação mínima para saber votar, produzir e se conformar não é saudável dentro das perspectivas atuais da nossa sociedade. Os indivíduos em sua totalidade devem saber lidar com situações complexas, não apenas a minoria.

Infelizmente, os nossos sistemas educacionais ainda não pensam dessa maneira. Observamos claramente que há uma lógica seletiva, já que os currículos são elaborados para selecionar quem será a elite de amanhã e não para formar as pessoas para a vida. Perrenoud considera que pessoas que adquirem uma compreensão do mundo e uma cultura geral são capazes de aprender depressa uma porção de coisas depressa. Portanto, a escola é levada a fazer as coisas de forma contrária. As matérias como álgebra e frações, apesar de poderem ser aprendidas mais tarde com mais facilidade, são ensinada logo nas séries iniciais, para que nas universidades esses conteúdos sequer tenham sido assimilados. Em sequência, nas universidades, não se prioriza o trabalho individualizado com o aluno. Assim, as pessoas demoram muito para aprender. Não é feita uma avaliação formativa, trabalha-se com grupos enormes, causando, novamente, uma ineficiência no ensino.

Todo professor deve prestar contas dos seus serviços para receber o seu salário. Receber um salário por seus serviços significa "aceitar as regras do jogo". Essa situação é bastante delicada pois, apesar de ter que dar uma devolutiva, espera-se que haja credibilidade o que é muito difícil em se tratando de educação. Por exemplo, de um professor da alfabetização, espera-se que no final do ano todos os alunos saibam ler. Então, para o professor, não basta seguir o programa, utilizar-se de bons métodos de avaliação, chegar no horário, não violentar os alunos, etc.

Se o professor utilizar-se do ensino por competências para realizar suas atividades, não será possível fazer algo formidável, mas será possível conseguir um melhor resultado dentro da situação. Ao pensar-se nas diferentes realidades sociais, conclui-se que 0 trabalho do professor não será o mesmo executado na favela, no campo, na cidade, etc. Não são as mesmas situações, a mesma realidade, os mesmos problemas. Nesse caso, o professor irá mobilizar toda a sua inteligência e motivação para tentar fazer o melhor possível dentro de cada situação que lhe é proposta.

Assim, torna-se necessário entender que, além dessas tarefas, o professor também deverá ser avaliado por suas competências, pois elas sim farão a diferença no final das contas, já que os alunos não aprendem sozinhos. Essas competências abrangem se ele sabe fazer uma avaliação formativa, se ele sabe planejar um programa, se ele sabe 
animar um grupo, se ele consegue entender quando um aluno está com dificuldade de aprendizagem ou está sendo resistente a ela, se ele sabe dialogar com a família quando necessário, dialogar com os próprios alunos. Sobre esse enfoque, a tarefa maior do professor, é aprender a pensar por si, a ser autônomo intelectualmente, a saber compreender o mundo, a se compreender, a esclarecer sua relação com o mundo. Todo o resto virá por acréscimo (Idem. Ibidem).

\section{Método de Pesquisa \\ Desenho do Estudo}

Essa pesquisa é um estudo de caso, pois expõe uma pesquisa realizada em um local e realidade específica, como coloca Yin (2001) o estudo de caso é uma estratégia de pesquisa que compreende um método que abrange tudo em abordagens especificas de coletas e análise de dados. Tem caráter descritivo, em virtude da coleta, análise e interpretação de dados; exploratório, porque visa descobrir o perfil e as competências previas dos alunos e natureza qualitativa e quantitativa. Sua natureza qualitativa é justificativa porque tem-se como objetivo identificar perfis diferentes indivíduos (GIL, 2002), e quantitativa, pela utilização de dados estruturados (MATAR, 2001).

\section{Local e Período do Estudo}

O presente estudo foi realizado em Instituição de Ensino de Educação Profissional e Tecnológica no período de dezembro de 2017 a maio de 2018.

\section{Instrumento de coleta e Análise de Dados}

Como instrumento de coleta de dados, aplicou-se aos alunos ingressantes em cinco cursos técnicos a distância um questionário utilizando o Google forms, o qual possuía 28 perguntas fechadas e abertas. $O$ link do questionário foi disponibilizado no ambiente virtual de aprendizagem - AVA, e os tutores enviara, mensagens e efetuaram ligações aos alunos, solicitando que respondessem o questionário.

\section{Discussão e Resultados}

A aplicação do questionário obteve 81 respondentes, que são alunos ingressantes nos cursos técnicos a distância em: Automação Industrial, Eletrotécnica, Logística, Redes de Computadores e Segurança do Trabalho, em diversas escolas espalhadas pelo estado de Goiás da Instituição de Ensino pesquisada. Mediante as respostas obtidas, foi possível, estabelecer o perfil dos alunos e se os mesmos já possuíam competências previas ligadas aos cursos que estavam iniciando.

\section{Perfil dos Alunos}

Os alunos em sua maioria são do sexo masculino, como demonstrado no gráfico 1, 51\% 
são casados e 56\% não possuem filhos. Possuem idade entre 21 a 30 anos.

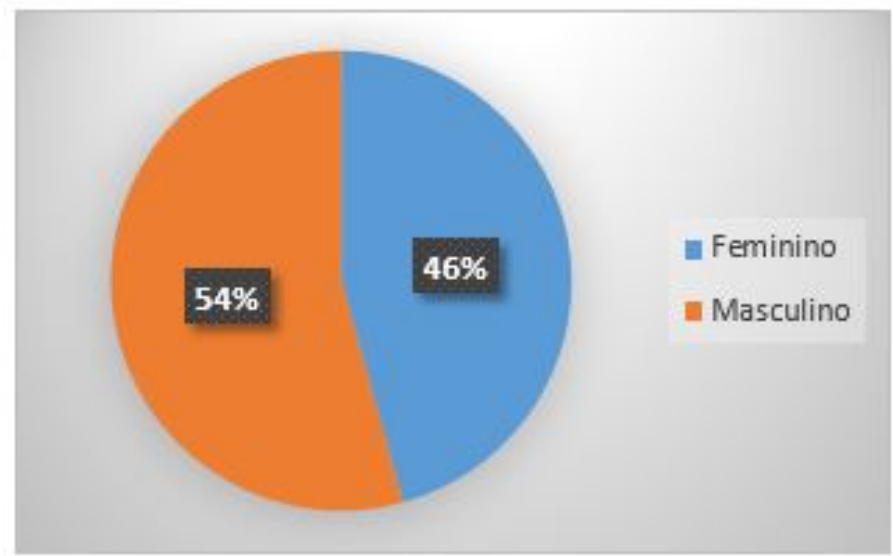

Gráfico 1 - Sexo. Fonte: Elaborado por DE SÁ FILHO, Paulo (2018).

Com relação ao grau de escolaridade, $57 \%$ dos alunos possui ensino médio completo, e a grande maioria é oriundo de escolas públicas, conforme o gráfico 2. Já, ao observar o nível de empregabilidade, $66 \%$ estão empregados. E faixa salarial varia de 1 a 3 salários mínimos, com exposto no gráfico 3.

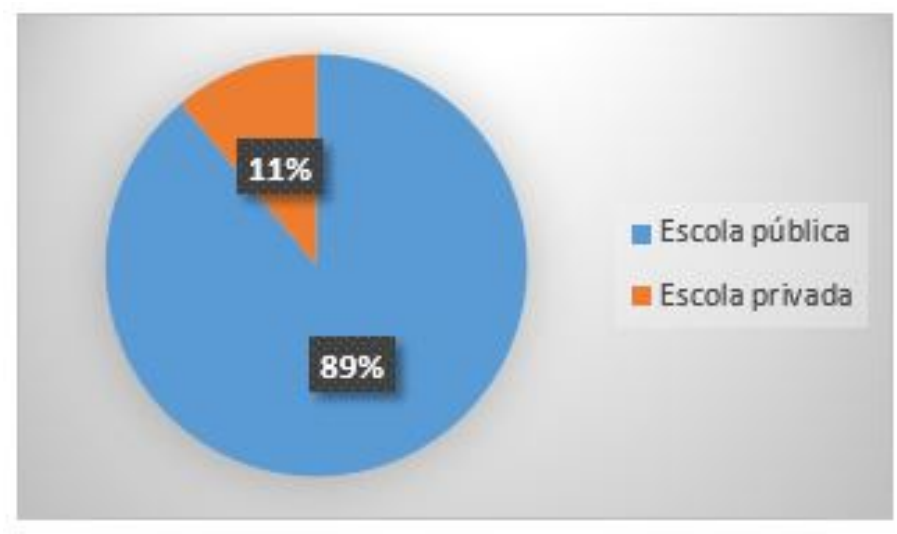

Gráfico 2 - Origem Escolar. Fonte: Elaborado por DE SÁ FILHO, Paulo (2018).

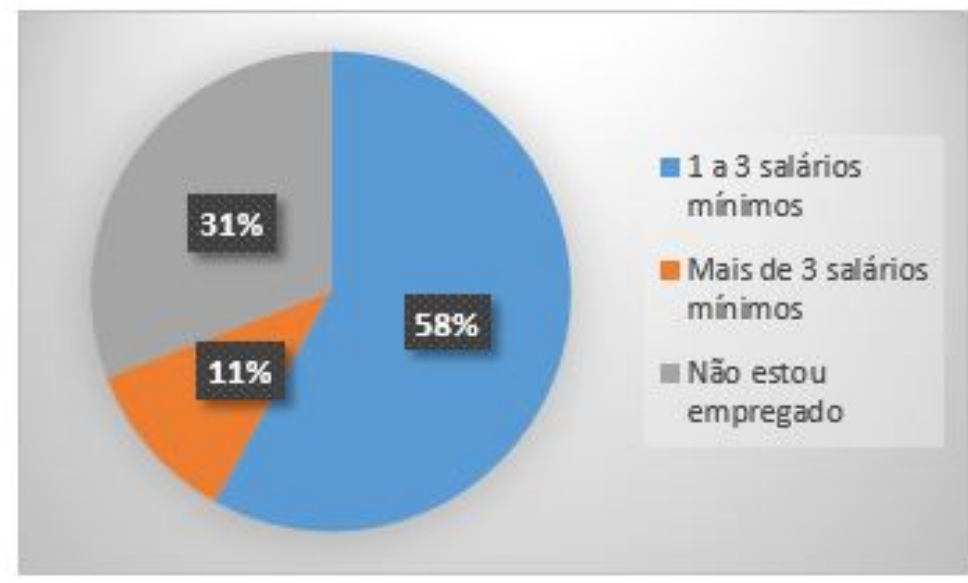

Gráfico 3 - Faixa Salarial. Fonte: Elaborado por DE SÁ FILHO, Paulo (2018).

Ao verificar a acessibilidade a informática e a internet, identificou que $90 \%$ dos alunos possuem computador, $88 \%$ acessam a internet na sua residência e que $93 \%$ utilizam também o celular para acessarem a internet, conforme demonstrado no gráfico 4 . 


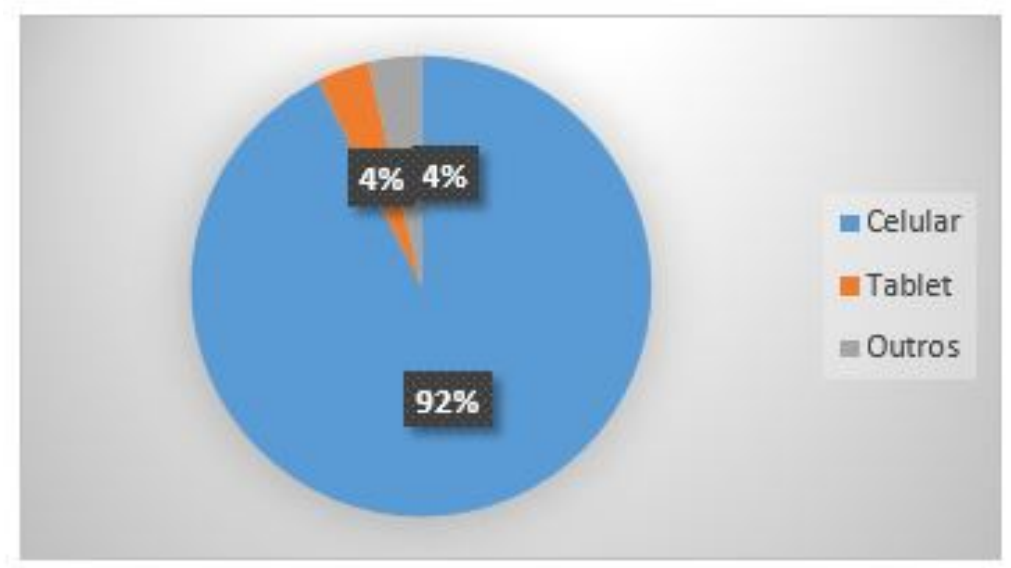

Gráfico 4 - Outra forma de acesso internet. Fonte: Elaborado por DE SÁ FILHO, Paulo (2018).

Outro fator importante observado nesse estudo é que $60 \%$ dos alunos responderam que a disponibilidade para estudo é durante o período noturno, e que $65 \%$ tem que deslocar até $30 \mathrm{~km}$ para os momentos presenciais na escola e utilizam de diversos meios para isso, conforme o gráfico 5.

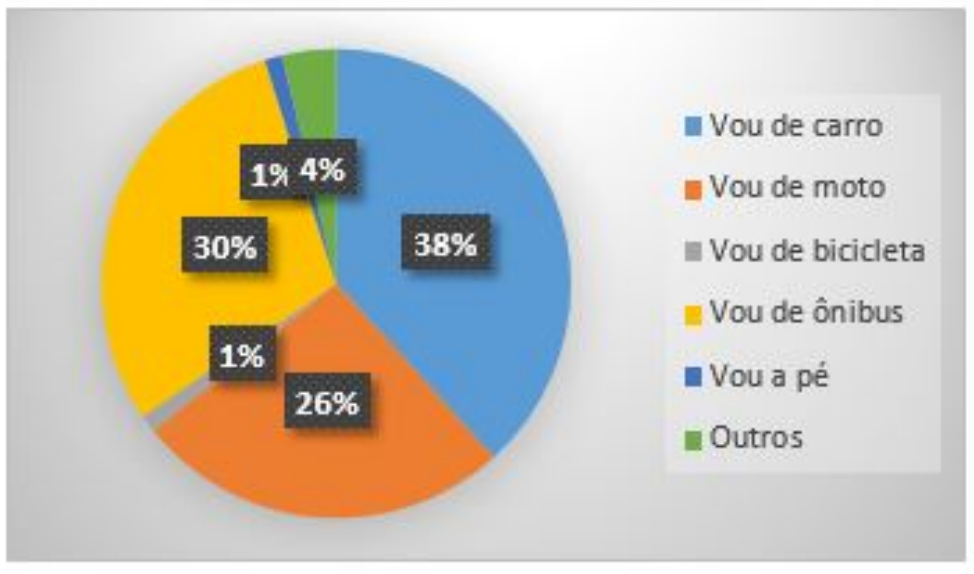

Gráfico 5 - Condução para MP. Fonte: Elaborado por DE SÁ FILHO, Paulo (2018).

Nota-se que os resultados relativos ao perfil dos estudantes estão em acordo ao perfil apresentado dos alunos de cursos técnicos e de cursos a distância, no que tange a maioria serem homens, motiva-se pela área dos cursos abordados, como diz Nassi-Calò (2015), há um marcante predomínio de homens, entre estudantes nas áreas de ciências duras, tecnologia, engenharia e matemática. A esse fato une-se que na formação profissional de acordo com o IBGE (2017) os homens apresentaram maiores percentuais do que as mulheres.

Outro ponto comum, é com relação a empregabilidade, que ao observarmos o CensoEaD.BR - 2016/2017, da Associação Brasileira de Educação a Distância - Abed, traz que a maioria dos alunos trabalham. Ressalta-se também, no que tange as formas de acesso, o IBGE (2018), traz que entre os usuários da Internet com 10 anos ou mais de idade, $94,6 \%$ se conectaram via celular. 
Para identificar se os alunos possuíam competências prévias ligadas aos cursos técnicos a distância que eles passariam a cursar, foi feito oito perguntas envolvendo conceitos, básicos, médios e avançados. Tais questionamentos foram vinculados a situações cotidianas dos alunos, para que pudessem mensurar de forma coerente 0 nível de experiência com o conceito abordado. Assim, mediante as respostas podermos estabelecer o nível de conhecimento prévio de cada aluno.

Dessa maneira, obtivemos os seguintes resultados, com relação aos conceitos básicos, temos expresso nos gráficos 6 e 7, aos conceitos medianos expomos nos gráficos 8 e 9 e aos conceitos avançados, nos gráficos 10 e 11 .
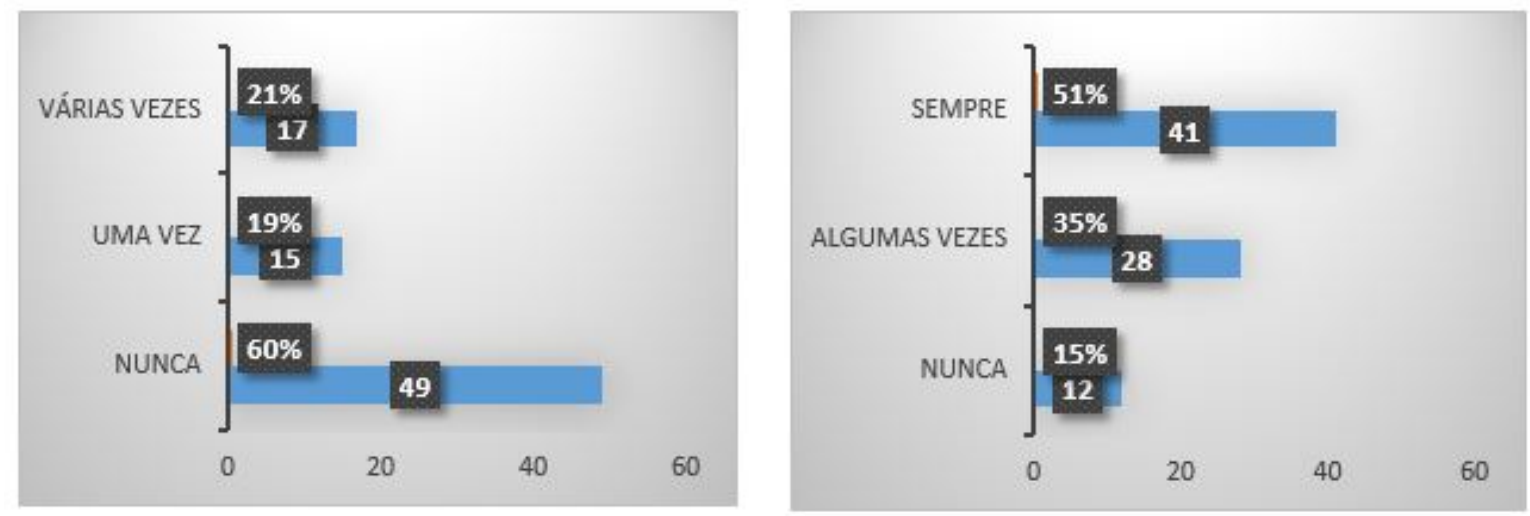

Gráficos 6 e 7 - Perg. 1 e 2: Conceito Básico. Fonte: Elaborado por DE SÁ FILHO, Paulo (2018).
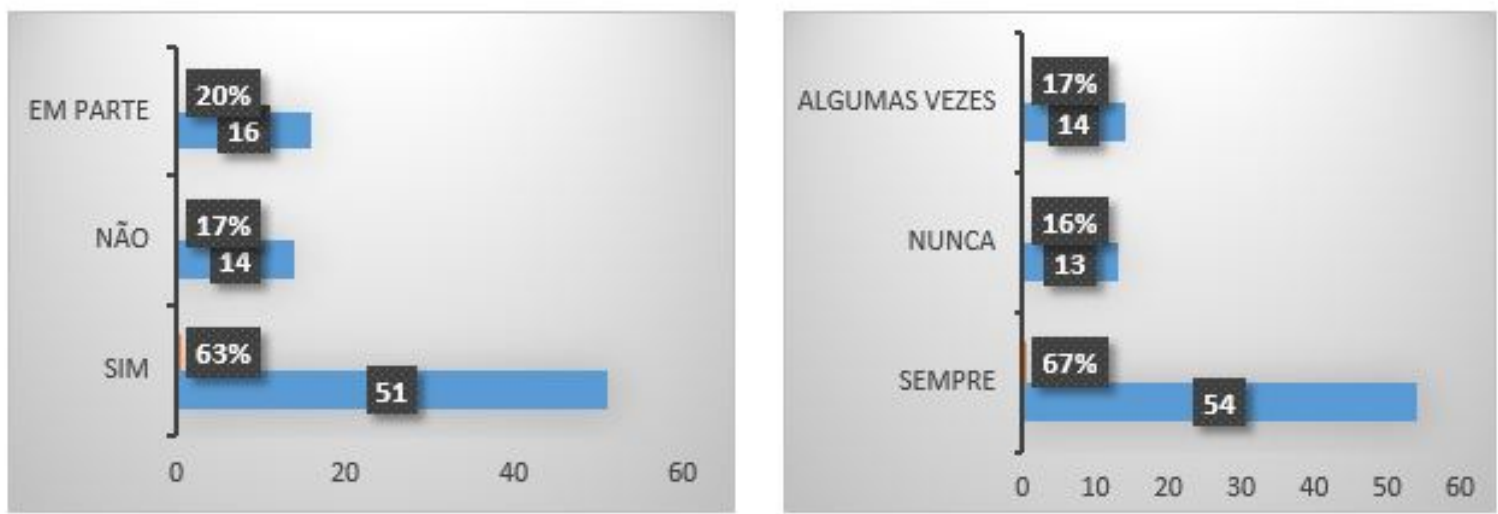

Gráficos 8 e 9 - Perg. 1 e 2: Conceito Médio. Fonte: Elaborado por DE SÁ FILHO, Paulo (2018).
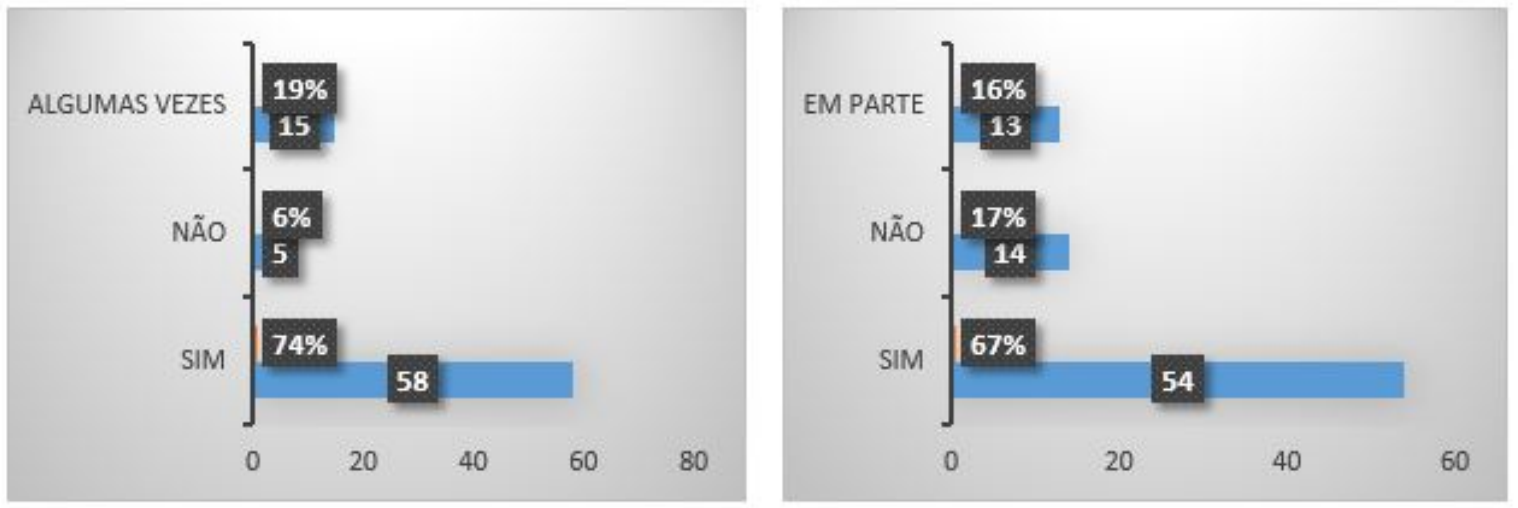
Gráf. 10 e 11 - Perg. 1 e 2: Conc. Avançado. Fonte: Elaborado por DE SÁ FILHO, Paulo (2018).

Percebe-se claramente, que os alunos possuem em certa medida conceitos prévios, fortalecendo assim, a abordagem vigotskiana que preconiza que devemos sempre levar em consideração os conhecimentos prévios dos alunos para realmente tenhamos ou venhamos propiciar uma aprendizagem significativa.

\section{Considerações Finais}

Nós enquanto educadores buscamos ao desenvolver esse questionário e aplica-lo aos alunos logo no início dos cursos, com intuito de identificarmos o perfil deles e suas competências previas ligadas a formação profissional a qual estavam adentrando. Com essas informações em mão pudemos desenhar situações de aprendizagens e atividades de acordo com a realidade dos alunos, estimulando, com isso, o aprendizado de todos e obtendo por meio da gestão dessas competências uma aprendizagem significativa.

Todavia sabemos que os resultados obtidos com essa pesquisa é apenas um pequeno passo, diante da grande jornada que temos que percorrer, rumo a uma aprendizagem significativa. Pois, desenvolver recursos, métodos, formas e etc., para que venhamos levar em consideração a vivencia dos alunos é fundamental no processo de ensinoaprendizagem. Somente, assim teremos êxito na construção de educação que seja emancipadora dos indivíduos, permitindo que eles possam ter uma consciência crítica diante da realidade a qual estão inseridos.

\section{Referências}

BRONCKART, Jean-Paul; DOLZ, Joaquim. A noção de competência: qual é sua pertinência para o estudo da aprendizagem nas ações de linguagem? In: DOLZ, Joaquim e OLLAGNIER, Edmée (Org.) O Enigma da Competência em Educação. Porto Alegre: Artmed, 2004.

YIN, Roberto K. Estudo de caso: planejamento e métodos. 2a Ed. Porto Alegre. Editora: Bookmam. 2001.

GIL, Antônio Carlos. Como elaborar projetos de pesquisa. 4. ed. São Paulo: Atlas, 2002.

IBGE. Instituto Brasileiro de Geografia e Estatística. Agência IBGE Notícias. Disponível em:<https://agenciadenoticias.ibge.gov.br/agencia-noticias/2013-agencia-de-noticias/rel eases/18992-pnad-continua-2016-51-da-populacao-com-25-anos-ou-mais-do-brasilpossuiam-apenas-o-ensino-fundamental-completo.html>. Acesso em: 10 abril 2018. IBGE. Instituto Brasileiro de Geografia e Estatística. Agência IBGE Notícias. Disponível em:<https://agenciadenoticias.ibge.gov.br/agencia-noticias/2013-agencia-de-noticias/rel eases/20073-pnad-continua-tic-2016-94-2-das-pessoas-que-utilizaram-a-internet-o- 
fizeram-para-trocar-mensagens.html>. Acesso em: 10 abril 2018.

MATAR, F. N. Pesquisa de marketing. 3.ed. São Paulo: Atlas, 2001.

NASSI-CALÒ, L. Inequidade de gêneros na ciência varia entre disciplinas [online].

SciELO em Perspectiva, 2015 [viewed 19 May 2018]. Available from: https://blog.scielo.o rg/blog/2015/03/08/inequidade-de-generos-na-ciencia-varia-atraves-das-disciplinas/ PERRENOUD, Philippe. Memória Roda Viva: Philippe Perrenoud. [19 de novembro, 2001]. São Paulo: Fundação de Amparo à Pesquisa do Estado de São Paulo. Entrevista concedida à Heródoto Barbeiro. 